AperTO - Archivio Istituzionale Open Access dell'Università di Torino

\title{
The therapy of chronic pouchitis
}

\section{This is the author's manuscript}

Original Citation:

Availability:

This version is available http://hdl.handle.net/2318/1706994

since 2019-07-19T16:09:23Z

Published version:

DOI:10.23736/S1121-421X.18.02551-5

Terms of use:

Open Access

Anyone can freely access the full text of works made available as "Open Access". Works made available under a Creative Commons license can be used according to the terms and conditions of said license. Use of all other works requires consent of the right holder (author or publisher) if not exempted from copyright protection by the applicable law. 


\section{The therapy of chronic pouchitis}

Journal: Minerva Gastroenterologica e Dietologica

Paper code: Minerva Gastroenterol Dietol-2551

Submission date: December 8, 2018

Article type: Editorial

Files:

1. Manuscript

Version: 1

Description: manoscritto

File format: application/octet-stream 


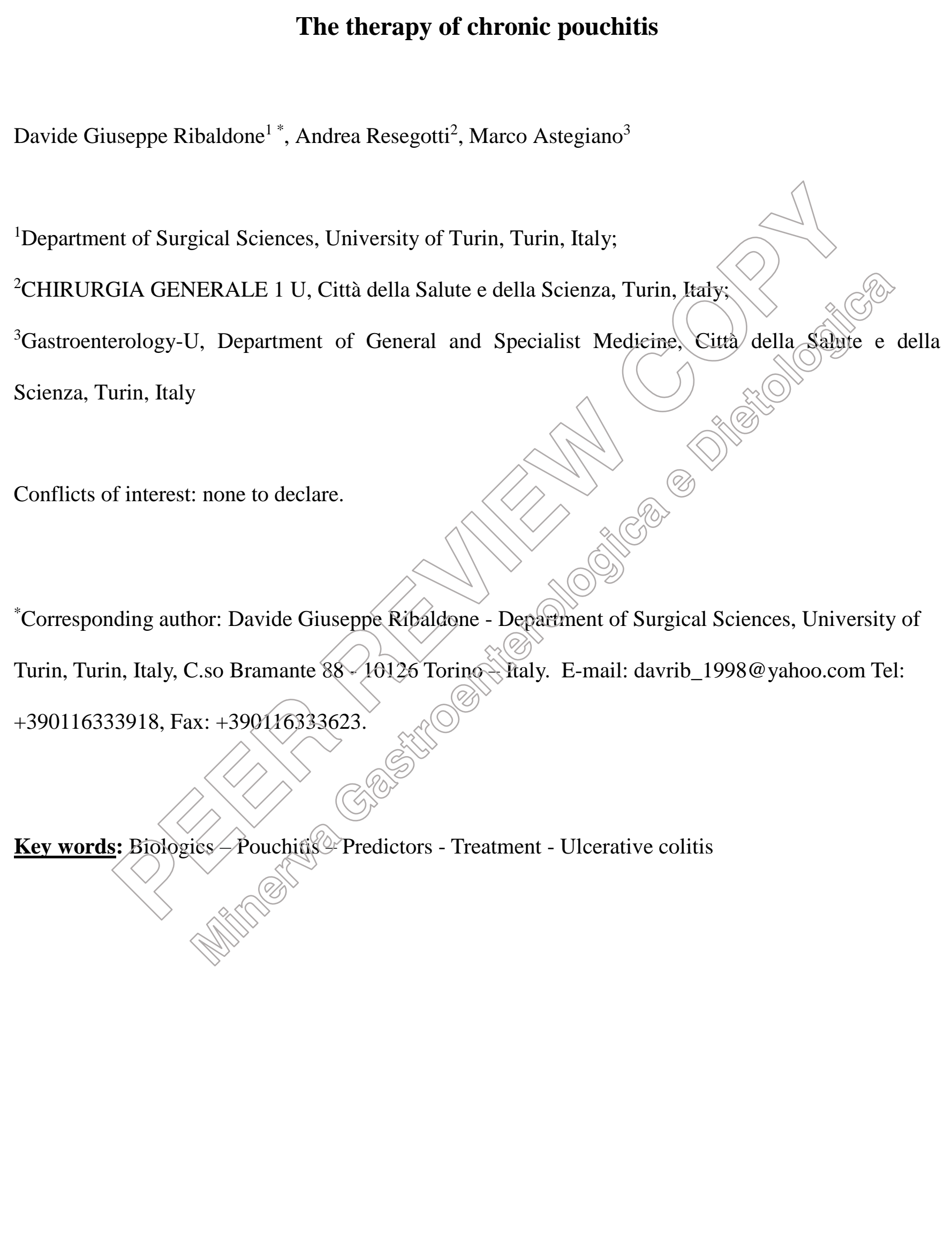

\section{The therapy of chronic pouchitis}


Ulcerative colitis (UC) is an inflammatory bowel disease characterized by inflammation restricted to

the large bowel mucosa. Up to one-quarter of patients with UC will eventually undergo total proctocolectomy. ${ }^{1}$

Since the first description by Parks in 1978, ileal pouch-anal anastomosis (IPAA) has become the surgical procedure of choice for both UC refractory to medical therapy and in those who develop colonic dysplasia or cancer and familial adenomatous polyposis (FAP). ${ }^{2}$

Since UC is primarily restricted to the large bowel, it was expected that IPAA will enable eradication of diseased and cure the UC. However, following the surgery up to $30 \%$ may develow chronic pouchitis. ${ }^{3}$

Pouchitis is clinically characterised by symptoms that include increased stool frequency, haematochezia, abdominal cramping, urgency, tenesmus. incontigence, fever and extraintestinal manifestations.

Pouchitis is a nonspecific inflammatory condition in the ileal pouch reservoir. ${ }^{4}$ The fact that pouchitis occurs more commonly in those who have a pouch for UC than for FAP suggests that both the immune system and its regulation have a role in the aetiology. Some evidence suggests that an abnormal mucosal immune response to altered micesflora in the ileal pouch leads to inflammation.

The diagnosis of pouchitis has no standard definition. The most commonly used criterion is the pouch disease activity index (PDAI). The PDAI is a composite score including clinical symptoms, endoscopic findings and histological findings. A score greater than 7 is required for a diagnosis of pouchitis. Differential diagnosis of pouchitis include pouch ischemia, pouch stenosis, impaired pouch emptying, infectious diarrhea such as cytomegalovirus or clostridium difficile, Crohn's disease (CD) of the pouch, adhesions.

Controversy remains about anal and vaginal fistulas in patients with a pouch and what they represent. It 


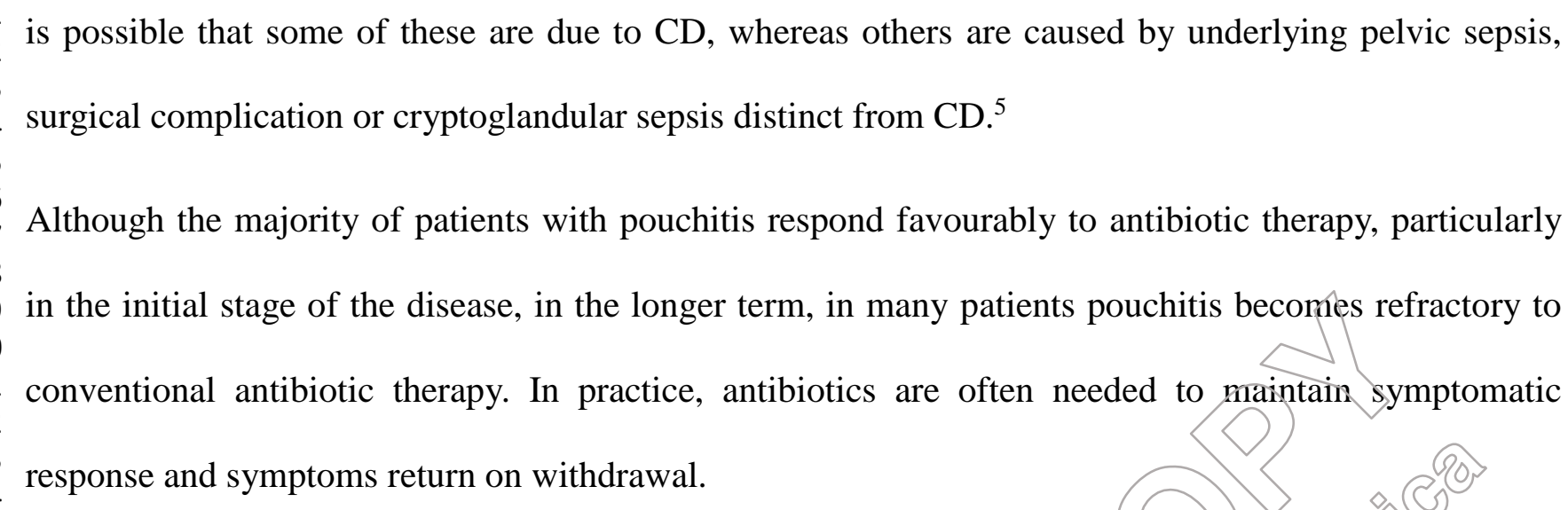

Chronic pouchitis has no standard definition, but is often defined as the need for antibiotics for greater than 4 weeks with evidence of pouchitis. ${ }^{6}$ Chronic pouchitis develops in approximately $5 \%-19 \%$ of patients who either become dependent on antibiotics for symptom relief or have symptoms refractory to conventional therapies. ${ }^{7}$

Regarding primary prophylaxis of pouchitis, a low-carbohydrates low-fibre, and high-protein diet is recommended at baseline. In a randomized trial of 40 consecutive patients who underwent IPAA were given either probiotic therapy with VSL\#3, 1 packet (900 billion bacteria including Lactobacillus species, Bifidobacterium supplementation, Streptococcus salivarius supplementation, and Thermophilus supplementationy each diay or placebo for 12 months after ileostomy closure. VSL\#3 reduced the incidence of acute pgrchitis - only $10 \%$ of patients that received VSL\#3 (2/20) developed pouchitis, while $40 \%$ of the placebo group $(8 / 20)$ developed pouchitis $(\mathrm{P}<0.05){ }^{8}$

The first-line treatnent of acute pouchitis is empirical with antibiotics. Ciprofloxacin and metronidazole are the most commonly used, often generating a rapid dramatic response after a 2- to 4week course ( $70 \%$ of remission), with rifaximin and tinidazole being alternative agents to try in combination. Long-term use of antibiotics is poorly effective in achieving clinical remission for those patients with chronic pouchitis, but may be useful at keeping symptoms under control. ${ }^{9}$

55 Patients with antibiotic-refractory pouchitis may need to opt for salicylates, corticosteroids (i.e. 
1

2 3

budesonide), immunosuppressive drugs (i.e. azathioprine), or anti-TNF biologics.

Treatment of a recurrent episode of pouchitis should first be directed toward a repeat trial of antibiotics or a trial of combination antibiotic therapy.

Patients who continue to have relapses of pouchitis despite antibiotics at least 3 times each year are considered to have a chronic antibiotic-dependent pouchitis. These patients often require rotating courses of antibiotics, and these patients should also be placed on maintenance therapy.

A randomized controlled trial of 40 patients given 2 packets/day of VSL\#3 (600 bilion bacteria) or placebo showed that VSL\#3 was able to prevent a relapse during the study adlow-up period of 9 months (15\% of VSL\#3 had relapse vs $100 \%$ placebo, $\mathrm{P}>0.021) .8$

Oral budesonide is used at $9 \mathrm{mg} /$ day for 3 months, then $3-6 \mathrm{mg}$ /ataffor maintenance. Steroid therapy with budesonide has been tried in multiple smali studies withreported remission rates of $60 \%-75 \%$. Another steroid, beclomethasone dipioprionate, was tried in an open-label study of 10 patients for 8 weeks, and $80 \%$ of patients achieved remission based on a total PDAI $<4 .{ }^{10}$

Topical mesalazine has been given to patients with pouchitis with clinical and endoscopic improvement.

Immunosuppression with immunomodulators such as azathioprine or 6-mercaptopurine has also been used by some providers, atthough little data exists regarding the use of immunomodulator monotherapy for pouchitis.

Studies including small numbers of patients (often fewer than 20), and mostly retrospective in design have demonstrated that infliximab appears to have good clinical effectiveness in selected patients with pouchitis, achieving up to $80 \%$ short-term and around 50\% long-term response. Some data suggest that potentially, in some patients started on anti-TNF medications for pouchitis, we may be delaying 
inevitable surgery rather than having a meaningful impact on disease course. ${ }^{11}$

3

4

6

9 10

In an open-label, prospective, single arm, multicentre study was evaluated the efficacy of granulocyte and monocyte apheresis in patients that had active pouchitis while on conventional medical therapy including corticosteroids, amino-salicylates and anti-TNF biologics in addition to antíbiotics. Nearly half of the patients (46\%) responded to the treatment, but without achieving complete remission. ${ }^{12}$ In a case series of 5 patients receiving multiple faecal microbiota transplantation (rangect -7 ) via flexible sigmoidoscopy had symptom resolution in $80 \%$ (4/5) within 4 weeks, and $750 \%$ (3/4) of the responders remained in remission for 3 months. ${ }^{13}$

Finally, case series about emerging role of vedolizumab or ustekinumab as a treatment option for chronic have been published..$^{14,15}$

In conclusion, treatment of chronic refractory pouchitis remains arr unmet need of UC' management.

\section{References}

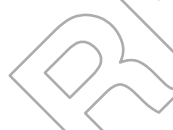

1. Solberg IC, Lygren I, Jahnsen J, Aadland E, Høie O, Cvancarova M, et al. Clinical course during the first 10 years of ulcerative colitis: results from a population-based inception cohort (IBSEN Study). Scand Jostroenterol. 2009 Jan 8;44(4):431-40.

2. Parks AG, Nicholls RJ. Proctocolectomy without ileostomy for ulcerative colitis. Br Med J. 1978 Jul 8;2(6130):85-8.

3. de Buck van Overstraeten A, Wolthuis AM, Vermeire S, Van Assche G, Laenen A, Ferrante M, et al. Long-term functional outcome after ileal pouch anal anastomosis in 191 patients with ulcerative colitis. J Crohn's Colitis. 2014 Oct;8(10):1261-6. 
4. Shen B, Fazio VW, Remzi FH, Delaney CP, Bennett AE, Achkar J-P, et al. Comprehensive Evaluation of Inflammatory and Noninflammatory Sequelae of Ileal Pouch-Anal Anastomoses. Am J Gastroenterol. 2005 Jan;100(1):93-101.

5. Lightner AL, Fletcher JG, Pemberton JH, Mathis KL, Raffals LE, Smyrk T. Crohn's Disease of the Pouch: A True Diagnosis or an Oversubscribed Diagnosis of Exclusion? Dis Colon Rectum. 2017 Nov;60(11):1201-8.

6. GIONCHETTI P, RIZZELLO F, POGGIOLI G, PIERANGELI F, LAURETI S, MOOORSELLI C, et al. Oral budesonide in the treatment of chronic refractory pouchitis. Aliment Pharmacol Ther. 2007 Feb 28;25(10):1231-6.

7. Shen B, Lashner BA. Diagnosis and treatment of pouchitis. Gastroenterol Hepatol (N Y). 2008 May;4(5):355-61.

8. Gionchetti P, Rizzello F, Helwig U, Venturi A, Lammers KM, Brigidi P, et al. Prophylaxis of pouchitis onset with probiotic therapy: double-blind, placebo-controlled trial. Gastroenterology. 2003 May; 124(5):1202-9/6)

9. Segal JP, Poo SX, McLaughin SD, Haiz OD, Clark SK, Hart AL. Long-term follow-up of the use of maintenance antibiotic therapy for chronic antibiotic-dependent pouchitis. Frontline Gastroenterol. 2018 Jan 31;0(2):flgastro-2017-100913.

10. Gionchetij P, Calabiese C, Calafiore A, Praticò C, Poggioli G, Laureti S, et al. Oral beclomethasone dipropionate in chronic refractory pouchitis. J Crohn's Colitis. 2014 Jul;8(7):649-53.

11. Segal JP, Penez L, Mohsen Elkady S, Worley GHT, McLaughlin SD, Mullish BH, et al. Long term outcomes of initial infliximab therapy for inflammatory pouch pathology: a multi-Centre retrospective study. Scand J Gastroenterol. 2018 Sep 29;1-8.

12. Yamamoto T, Tanaka T, Yokoyama T, Shimoyama T, Ikeuchi H, Uchino M, et al. Efficacy of 
granulocyte and monocyte apheresis for antibiotic-refractory pouchitis after proctocolectomy for ulcerative colitis: an open-label, prospective, multicentre study. Therap Adv Gastroenterol. 2017 Feb 25;10(2):199-206.

13. Stallmach A, Lange K, Buening J, Sina C, Vital M, Pieper DH. Fecal Microbiota Transfer in Patients With Chronic Antibiotic-Refractory Pouchitis. Am J Gastroenterol 2016 Mar 28;111(3):441-3.

14. Philpott J, Ashburn J, Shen B. Efficacy of Vedolizumab in Patients with Antibiotic and Antitumor Necrosis Alpha Refractory Pouchitis. Inflamm Bowel Dis. 2017 Jan;23(1):E5-6.

15. Peter J, Zeitz J, Stallmach A. Ustekinumab Rescue Therapy in a Patient With Chronic Refractory Pouchitis. J Crohn's Colitis. 2018 Jai $30 ; 12(8): 1008-9$.(8)

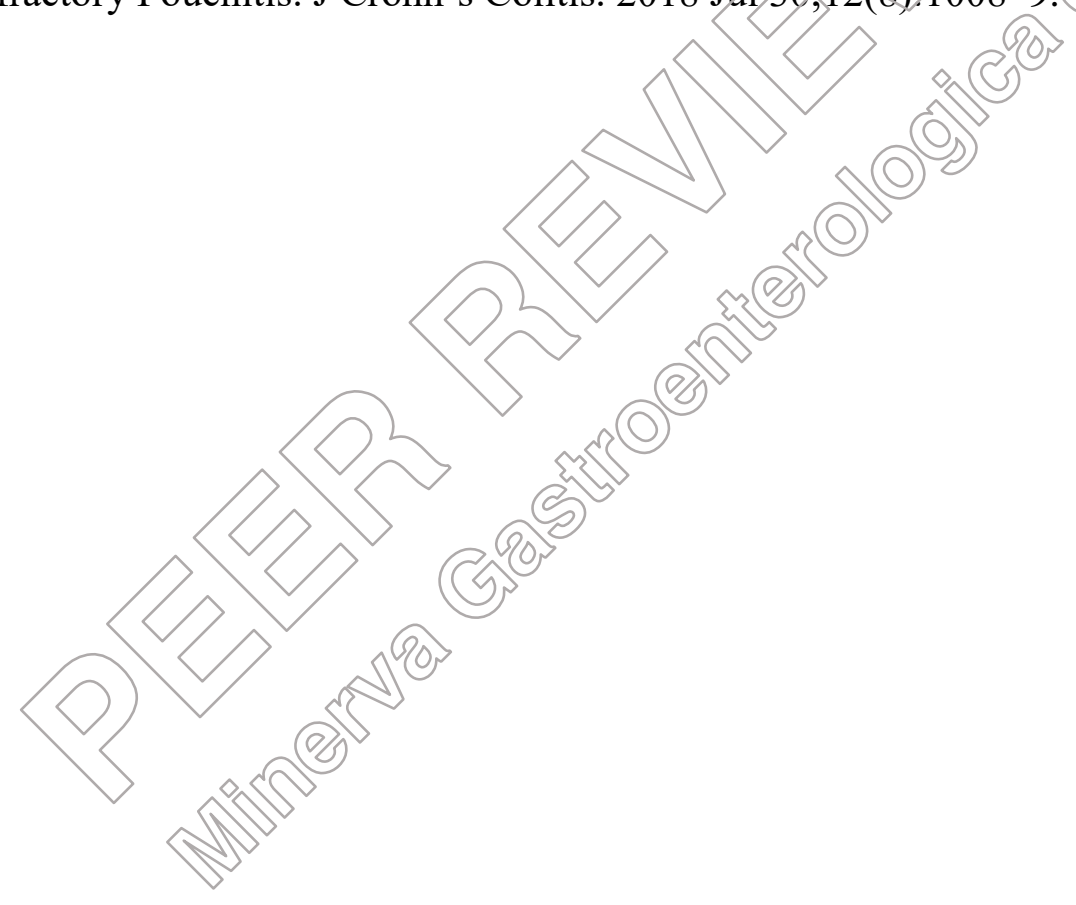

